10

\title{
Разрушение легированного тетрабората лития под воздействием радиации и лазерного излучения
}

\author{
(С) Ю.Г. Вайнер ${ }^{1,2}$, Н.Ю. Верещагина ${ }^{3}$, М.И. Данилкин ${ }^{3}$, В.М. Коршунов ${ }^{3,4}$, Ю.А. Репеев ${ }^{1}$, А.С. Селюков ${ }^{3,5}$ \\ ${ }^{1}$ Институт спектроскопии РАН, \\ 108840 Троицк, Москва, Россия \\ ${ }^{2}$ Научно-исследовательский университет Высшая школа экономики, \\ 101000 Москва, Россия \\ ${ }^{3}$ Физический институт им. П.Н. Лебедева РАН, \\ 119991 Москва, Россия \\ ${ }^{4}$ Московский государственный технический университет им. Н.Э. Баумана, \\ 105005 Москва, Россия \\ ${ }^{5}$ Московский фризико-технический институт (Государственный университет), \\ 141701 Долгопрудный, Московская обл., Россия \\ e-mail: vainer@isan.troitsk.ru
}

Поступила в редакцию 25.02.2019 г.

В окончательной редакции 25.02.2019 г.

Принята к публикации 15.03.2019 г.

Представлены результаты изучения деградации термолюминесцентных материалов $\mathrm{Li}_{2} \mathrm{~B}_{4} \mathrm{O}_{7}: \mathrm{Be}+\mathrm{Mn}$ и $\mathrm{Li}_{2} \mathrm{~B}_{4} \mathrm{O}_{7}: \mathrm{Zn}+\mathrm{Mn}$ под воздействием радиации (импульсный электронный пучок) и лазерного излучения. Обнаружено, что в результате воздействия высоких доз радиации структура изучаемых образцов частично приобретает аморфный характер, при этом в оптических свойствах эффект радиационного воздействия проявляется в возникновении зеленой люминесценции, обусловленной центрами марганца в тетраэдрическом окружении. При последующем облучении лазером с длиной волны излучения $350 \mathrm{~nm}$ происходит дальнейший распад центров люминесценции вследствие фотохимического окисления марганца $\mathrm{Mn}^{2+} \rightarrow \mathrm{Mn}^{3+}$. Показано, что материал $\mathrm{Li}_{2} \mathrm{~B}_{4} \mathrm{O}_{7}: \mathrm{Be}+\mathrm{Mn}$ имеет меньшую радиационную стойкость, чем $\mathrm{Li}_{2} \mathrm{~B}_{4} \mathrm{O}_{7}: \mathrm{Zn}+\mathrm{Mn}$.

Ключевые слова: тетраборат лития, термолюминесценция, радиационная аморфизация кристаллической структуры, лазерная деградация центров люминесценции

DOI: $10.21883 /$ OS.2019.07.47938.109-19

\section{Введение}

Тетраборат лития $\mathrm{Li}_{2} \mathrm{~B}_{4} \mathrm{O}_{7}$ используется в различных областях науки и техники. В частности, он применяется в качестве нелинейного кристалла для генерации гармоник и суммарных частот лазерного излучения [1-4], а также в качестве материала для тканеэквивалентных термолюминесцентных детекторов радиации (в последнем случае тетраборат лития намеренно легируют различными примесями: $\mathrm{Mn}$ [5-21], Ag [8,15,22-30], $\mathrm{Cu}[15,18,27-37])$. Радиационные дефекты в тетраборате лития достаточно хорошо изучены [38-45], но при этом не было попыток обобщения механизмов разрушения кристаллической структуры, в особенности при воздействии совершенно различных факторов - лазерного излучения и ионизирующей радиации. Нелегированные монокристаллы тетрабората лития обладают высокой радиационной стойкостью ко всем видам излучения $[11,38]$. Ситуация меняется, когда внесены примеси (например, для получения требуемых термолюминесцентных свойств). Дисбаланс центров захвата для носителей заряда различных знаков может играть существенную роль в снижении радиационной стойкости. Так, избыток центров захвата для электронов при недостатке дырочных ловушек может приводить к разрушению кристаллической структуры под воздействием ионизирующего излучения [45]. Однако мы наблюдали деградацию радиационно-поврежденного материала также и под действием коротких (1.5 ps) лазерных импульсов, что заставило нас исследовать взаимосвязь механизмов разрушения кристаллической структуры при различных воздействиях.

\section{Материалы и техника эксперимента}

В работе использовались образцы керамики тетрабората лития, последовательно легированные двумя примесями: бериллием и марганцем $\left(\mathrm{Li}_{2} \mathrm{~B}_{4} \mathrm{O}_{7}: \mathrm{Be}+\mathrm{Mn}\right)$ либо цинком и марганцем $\left(\mathrm{Li}_{2} \mathrm{~B}_{4} \mathrm{O}_{7}: \mathrm{Zn}+\mathrm{Mn}\right)$. Количество введенных примесей было $0.2 \mathrm{~mol} \%$ для марганца и цинка и $0.3 \mathrm{~mol} . \%$ для бериллия. Методика приготовления образцов способом последовательного легирования описана в работе [46] и в патенте [47]. Керамика состоит из небольших кристаллов тетрабората лития (характерный размер 0.010-0.025 mm), связанных в единое целое незначительным количеством стеклообразной фазы, содержащей диоксид кремния. Рентгеноструктурный анализ показывает, что при повышении температуры спекания керамики до примерно 1160-1170 K шири- 
на рефлексов перестает уменьшаться, и кристаллы в составе керамики оказываются разупорядочены лишь незначительно [17].

Для измерения кривых термостимулированной люминесценции (ТСЛ), а также для изучения радиационной деградации образцы облучали импульсным источником ускоренных электронов РАДАН-ЭКСПЕРТ (энергия электронов 90-240 keV, длительность импульса $2 \mathrm{~ns}$, флюэнс $5 \cdot 10^{11}$ электронов за 1 импульс [48]). Кривые ТСЛ измеряли с помощью считывателя термолюминесцентных детекторов ДВГ-2М („Доза“). Считыватель доработали для измерений больших доз и спектров свечения. Для уменьшения нагрузки на ФЭУ (9924В, спектральный диапазон 290-650 nm) его диафрагмировали (примерно 1:50). Между ФЭУ и нагревателем установили вставку с кварцевой линзой, позволявшую отвести часть излучения через кварцевый световод на портативный спектрометр Ocean Optics Maya2000Pro. Спектрометр регистрировал спектральный состав пиков ТСЛ в диапазоне $230-1000 \mathrm{~nm}$ при скорости нагрева $2 \mathrm{~K} / \mathrm{s}$. Высокая скорость нагрева и большая доза радиации обеспечивали уровень интенсивности свечения, достаточный для уверенной регистрации спектров. Для измерения кривой ТСЛ, как правило, достаточно одного импульса электронного ускорителя $\left(\sim 2 \mathrm{kGy} / \mathrm{cm}^{2}\right)$, а для измерения спектрального состава пиков ТСЛ требовалось до восьми таких импульсов.

Спектры фотолюминесценции измерялись на установке, состоящей из двойного монохроматора СДЛ-1 с ФЭУ Hamamatsu H8259-01. Для возбуждения использовалась $2 \mathrm{~kW}$ ксеноновая лампа и монохроматор МДР-23, с помощью которого сканировались спектры возбуждения люминесценции.

Для возбуждения люминесценции и исследования лазерного разрушения материала использовалось лазерное излучение $(350 \mathrm{~nm})$, полученное удвоением частоты лазера на титан-сапфире $(700 \mathrm{~nm})$ Mira 900-Р. Длительность импульсов на полувысоте составляла $\sim 2 \mathrm{ps}$, для основного излучения и $\sim 1.5 \mathrm{ps}$ для излучения удвоенной частоты. Излучение с длиной волны $350 \mathrm{~nm}$ фокусировалось на выбранный микрокристалл в керамическом образце микрообъективом с кратностью х40 и с числовой апертурой $\mathrm{N}_{\mathrm{A}}=0.6$. Мощность подаваемого на микрокристалл излучения составляла $\sim 2 \mathrm{~mW}$, а диаметр пятна $\sim 2 \mu \mathrm{m}$, что соответствует плотности мощности $\sim 60 \mathrm{~kW} / \mathrm{cm}^{2}$ и почти на шесть порядков меньше порога прямого лазерного разрушения кристаллов тетрабората лития [11]. Флуоресцентное свечение микрокристалла собиралось этим же объективом и направлялось на входную щель светосильного спектрографа с компенсацией астигматизма IHR-550 (Horiba). Спектр регистрировался высокочувствительной ПЗСкамерой от Princeton Instruments: PyLoN Spec-10 2KBUV $(2048 \times 512$ пикселей, $7 \times 28 \mathrm{~mm})$. Для контроля фокусировки излучения на выбранном микрокристалле выходное излучение временно переводилось зеркалом на цветную CMOS-камеру.

\section{Результаты и их обсуждение}

Радиационная деградация тетрабората лития может быть легко обнаружена по кривым термолюминесценции. При этом разными авторами было отмечено, что облучение и последующее термоциклирование образцов, содержащих марганец, вызывает сдвиги дозиметрического пика ТСЛ как в сторону более высоких $[11,45]$, так иногда и в сторону более низких температур [21]. Здесь переплетается целый ряд различных явлений. Вопервых, очень часто марганец распределен не только неоднородно, но и неравновесно, приходя в некое равновесие по мере облучения и термоциклирования. В этом случае как раз и может наблюдаться сдвиг дозиметрического пика ТСЛ в низкотемпературную область, поскольку среднее расстояние между электронными и дырочными центрами захвата может уменьшаться. Чаще всего неравновесное распределение примесей в монокристаллах связано с технологией их выращивания. Длительный отжиг образцов при температурах порядка $970 \mathrm{~K}$ мог бы улучшить распределение марганца, поскольку марганец может достаточно свободно перемещаться по кристаллической решетке [20]. Что касается высокотемпературного сдвига пика ТСЛ, то его можно объяснить вовлечением агломерированного марганца в процесс высвечивания запасенной энергии: чем больше доза, тем больший отрицательный заряд накапливается на границах положительно заряженных кластеров марганца, и отталкивание дырок перестает блокировать процесс рекомбинации. Тем не менее дыркам необходимо преодолеть дополнительный транспортный барьер, отчего пик ТСЛ сдвигается к более высоким температурам $[17,45]$. Этот случай обычно сопровождается сверхлинейной зависимостью пика ТСЛ от дозы радиации. При этом поведение керамики, подвергавшейся длительному спеканию, отличается обратимостью и воспроизводимостью, чем и пользуются в термолюминесцентной дозиметрии.

Наконец, существуют и необратимые изменения в кривой ТСЛ, и именно они указывают на радиационную деградацию материала. Об этих изменениях и пойдет речь.

На рисунке 1 показано формирование высокотемпературных пиков ТСЛ в процессе наращивания суммарной дозы облучения образцов. Последовательное многократное облучение и высвечивание запасенной энергии приводит к формированию новых дырочных центров захвата. Знак процесса может быть определен благодаря достаточно надежно идентифицированному методом ЭПР дырочному центру захвата на кислороде, расположенном вблизи бериллия, замещающего бор [49]. Основной пик ТСЛ при $580 \mathrm{~K}_{\text {у Li }} \mathrm{L}_{4} \mathrm{O}_{7}: \mathrm{Be}+\mathrm{Mn}$ хорошо совпадает с термическим распадом соответствующих дырочных ЭПР-центров [49]. При этом, как видно из верхнего ряда рис. 1, во всех процессах светит марганец, около которого, по-видимому, захвачен электрон. Что касается высокотемпературных плеч, формируемых под 

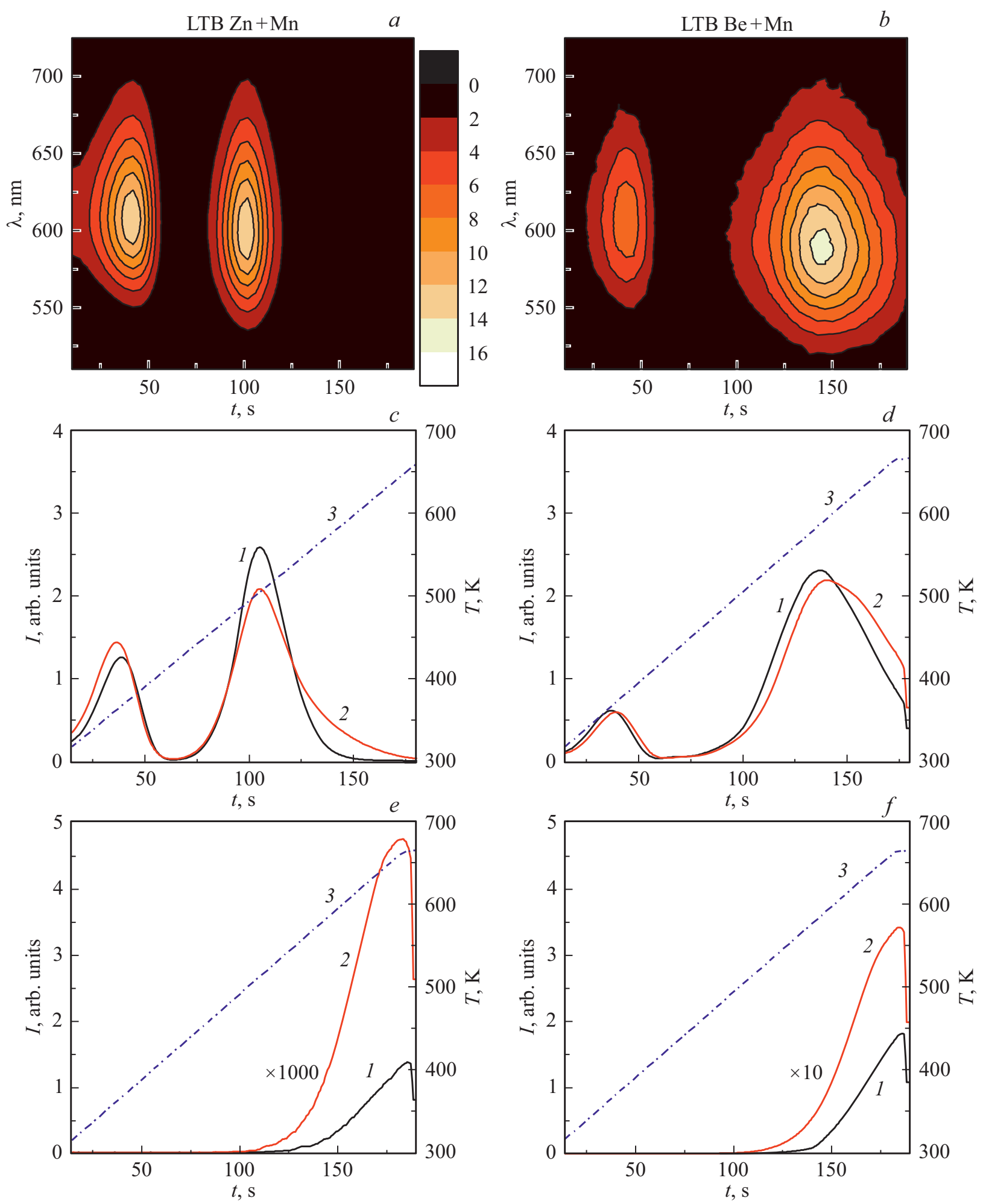

Рис. 1. Термостимулированная люминесценция $\mathrm{Li}_{2} \mathrm{~B}_{4} \mathrm{O}_{7}: \mathrm{Zn}+\mathrm{Mn}(a, c, e)$ и $\mathrm{Li}_{2} \mathrm{~B}_{4} \mathrm{O}_{7}: \mathrm{Be}+\mathrm{Mn}(b, \quad d$, $f)$ : карты изменения спектрального состава $(a, b)$ ТСЛ; динамика ее интенсивности (c, $d$, кривые 1 , сплошная линия). Штрихпунктирная линия 3 показывает динамику нагревания $(c-f)$. Кривые $2(c, d)$ соответствуют ТСЛ образцов, неоднократно подвергавшихся радиационному облучению (суммарная плотность дозы от 20 до $\left.50 \mathrm{kGy} / \mathrm{cm}^{2}\right)$. Для лучшей визуализации высокотемпературных пиков на $(e, f)$ показаны кривые, снятые повторно, без дополнительного облучения - до (1) и после (2) накопления большой суммарной дозы. 
действием радиации и термоциклирования, то их природа, по предварительным данным ЭПР, тоже дырочная, но пока детально не изучена. Недавно была выяснена природа одного из самых высокотемпературных пиков, формируемого выше $600 \mathrm{~K}$. Этому пику соответствует распад дырочного центра на пероксидном мостике [45]. Формирование пероксидного мостика на месте общей вершины двух борокислородных тетраэдров связано с радиационной деградацией материала. Кислород на общей вершине двух тетраэдров представляет собой слабое звено в каркасе [9]. Когда два тетраэдра $\mathrm{BO}_{4}$ теряют кислород, являющийся их общей вершиной, его захватывает соседняя группа из двух тетраэдров. На месте распавшейся группы происходит аморфизация структуры. Оказавшийся поблизости марганец приобретает при этом свойства, характерные для него в стеклах, что проявляется и в люминесценции. В разрушенной радиацией кристаллической решетке тетрабората лития формируются новые марганцевые центры, дающие яркую зеленую фотолюминесценцию. Такая фотолюминесценция наблюдалась ранее в поврежденных радиацией легированных марганцем монокристаллах [21]. Интересен тот факт, что излучение „зеленого“ марганца никогда не возбуждается в рекомбинационных процессах, а возникает только лишь при возбуждении светом в области запрещенных переходов марганца, которые дают в этом случае более размытый и более интенсивный спектр возбуждения [21].

В наших образцах, подвергнутых облучению электронным пучком, тоже возникла зеленая люминесценция, которая постоянно усиливалась после многократных радиационных воздействий с последующим термовысвечиванием запасенной энергии. На рис. 2 вверху показана люминесценция „оранжевого“ и „зеленого“ марганца при лазерном возбуждении, а также ее деградация во времени под воздействием лазерного излучения. Интересно, что у $\mathrm{Li}_{2} \mathrm{~B}_{4} \mathrm{O}_{7}: \mathrm{Be}+\mathrm{Mn}$ зеленое излучение интенсивное, но и быстро деградирует, тогда как у $\mathrm{Li}_{2} \mathrm{~B}_{4} \mathrm{O}_{7}: \mathrm{Zn}+\mathrm{Mn}$ зеленое излучение практически отсутствует, и деградация люминесценции при облучении лазером лишь незначительная. Это согласуется со степенью разрушения материала под действием импульсного электронного пучка: образец с бериллием разрушается значительно быстрее, если судить по формированию высокотемпературных дырочных пиков ТСЛ. Спектры возбуждения люминесценции (рис. 2, второй и третий ряды) показали то же самое - для образца $\mathrm{Li}_{2} \mathrm{~B}_{4} \mathrm{O}_{7}: \mathrm{Zn}+\mathrm{Mn}$, имеющего слабую радиационную деградацию, изменений в спектре возбуждения для $\lambda_{\text {lum }}=600 \mathrm{~nm}$ практически не видно. Спектр возбуждения на $\lambda_{\text {lum }}=550 \mathrm{~nm}$ для $\mathrm{Li}_{2} \mathrm{~B}_{4} \mathrm{O}_{7}: \mathrm{Zn}+\mathrm{Mn}$ не имеет смысла, поскольку зеленая полоса люминесценции у него либо не видна совсем, либо выражена очень слабо, налагаясь на основную оранжевую люминесценцию. Что касается образца $\mathrm{Li}_{2} \mathrm{~B}_{4} \mathrm{O}_{7}: \mathrm{Be}+\mathrm{Mn}$, то в его спектрах возбуждения немного заметно перераспределение энергии возбуждения от разных переходов. Переход ${ }^{6} \mathrm{~A}_{1}(\mathrm{~S}) \rightarrow{ }^{4} \mathrm{AE}(\mathrm{G})$ виден во всех случаях, поскольку он малочувствителен к кристаллическому полю и взаимодействию с лигандами [54]. Однако зеленая люминесценция возбуждается при этом переходе эффективнее, чем оранжевая, отчего у образца с интенсивной зеленой полосой люминесценции этот переход в спектре возбуждения оранжевой полосы менее выражен. И наоборот, максимум возбуждения около $350 \mathrm{~nm}$ оказывается эффективнее для оранжевой полосы, а в спектре возбуждения зеленой полосы в этом месте появляется небольшой провал. Такое взаимодействие может косвенно указывать на то, что разные центры марганца оказались рядом и способны конкурировать за энергию возбуждения.

Природу зеленого и оранжевого излучения марганца обычно связывают с силой кристаллического поля: тетраэдрическое окружение марганца дает более слабое поле и зеленую люминесценцию, а октаэдрическое более сильное поле и оранжево-красную люминесценцию, хотя характер связей и расстояние до лигандов также вносят свой вклад [50,51]. Логично предположить, что в нашем случае зеленая люминесценция связана с переходом ${ }^{4} \mathrm{~T}_{1}(\mathrm{G}) \rightarrow{ }^{6} \mathrm{~A}_{1}(\mathrm{~S})$ у $\mathrm{Mn}^{2+}$ в тетраэдрическом окружении. Подобная люминесценция наблюдалась, например, в стеклах [52,53], где марганец при низких его концентрациях дает зеленую люминесценцию, а при высоких - оранжево-красную. Такое поведение объясняется тем, что оксид марганца в малых количествах может выступать в роли стеклообразователя наряду с оксидами кремния, бора или свинца. Поэтому в малых концентрациях марганец входит в стекла преимущественно в каркас, образуя тетраэдрические конфигурации с кислородом, а при высоких концентрациях ведет себя как модификатор, входя на типичные катионные позиции, у которых преобладает октаэдрическое окружение. При промежуточных концентрациях могут формироваться парные центры смешанного типа. Возникновение зеленой люминесценции, подобной той, что у марганца проявляется в стеклах, указывает на формирование в наших облученных образцах таких же центров $\mathrm{Mn}^{2+}$ в тетраэдрическом окружении, какие существуют в стеклах.

Стоит отметить два обстоятельства. Во-первых, не следует проводить параллели между тетраэдрическим $\mathrm{Mn}^{2+}$ в разрушенной решетке и тем $\mathrm{Mn}^{2+}$ на позиции бора, который предположительно существует в кристалле до его деградации [10,17-19]. Марганец на позиции бора должен являться акцептором электронов, образуя $\sigma$-связи с кислородом с участием $4 s-$ и $4 p$ орбиталей, а дополнительные $\pi$-связи образуются с участием $d$-электронов. Электронные оболочки марганца в этом случае полностью заполнены. Такой марганцево-кислородный комплекс будет недоступен ни прямым люминесцентным, ни прямым ЭПР исследованиям. Обычный метод ЭПР обнаружит его разве только по сверхтонкому расщеплению сигналов каких-то близко расположенных центров (например, как пытались это сделать авторы работы [18]). Что касается возможной генетической связи между марганцем на месте бора 

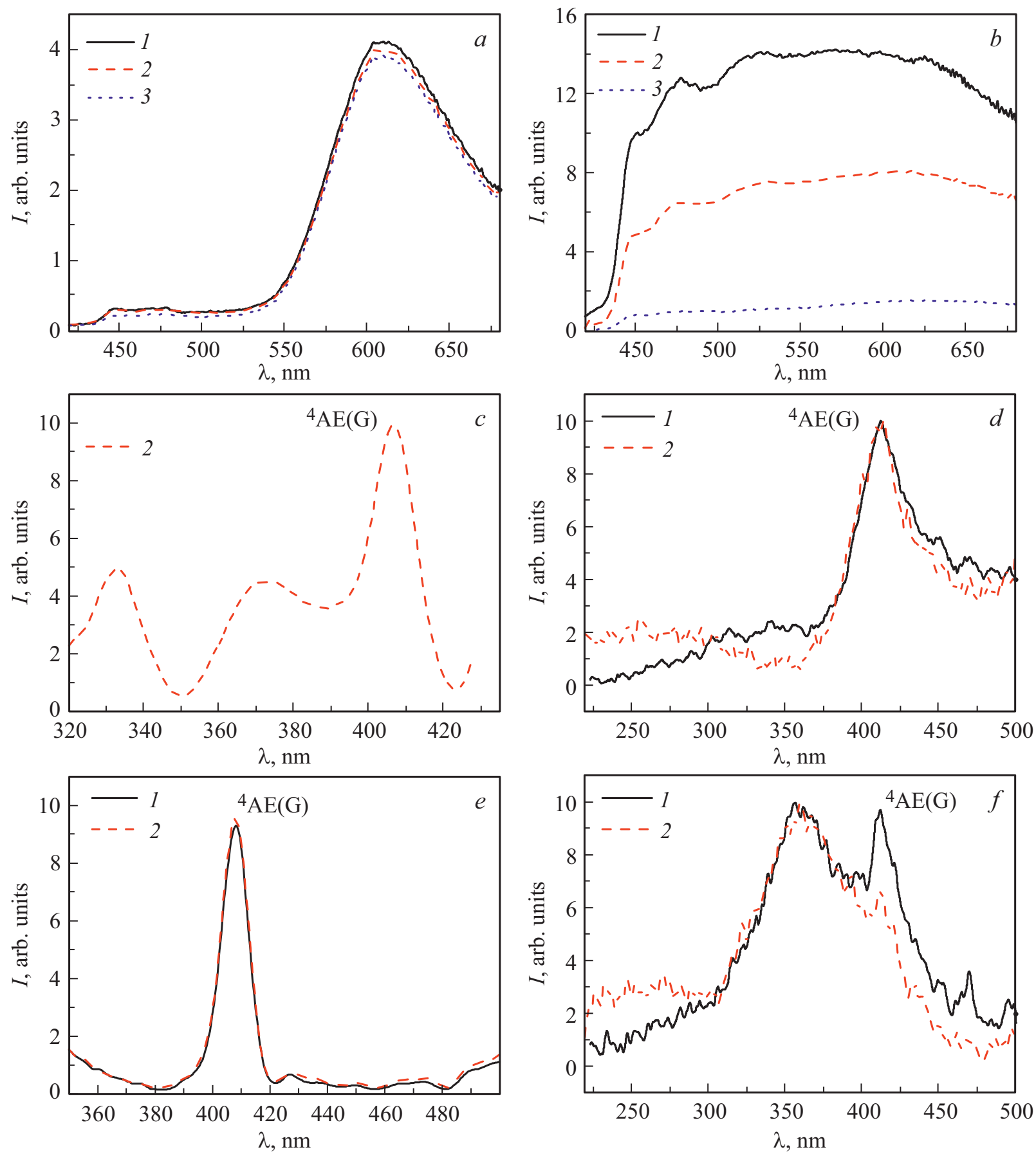

Рис. 2. Спектры люминесценции $(a, b)$ и ее возбуждения $(c-f)$ для образцов $\mathrm{Li}_{2} \mathrm{~B}_{4} \mathrm{O}_{7}: \mathrm{Zn}+\mathrm{Mn}(a, c, e)$ и $\mathrm{Li}_{2} \mathrm{~B}_{4} \mathrm{O}_{7}: \mathrm{Be}+\mathrm{Mn}_{(b, d, f)}$ в процессе радиационного и лазерного воздействия. $(a, b)$ - деградация люминесценции поврежденных радиацией образцов под лазерным возбуждением $350 \mathrm{~nm}$ в течение $0 \min (1) ; 2 \min (2) ; 10 \min (3)$. $(c-f)-$ спектры возбуждения для $\lambda_{\text {lum }}=550 \mathrm{~nm}(c, d)$ и $600 \mathrm{~nm}(e, f)$ до $(1)$ и после $(2)$ облучения большими дозами радиации.

до повреждения решетки и „зеленым“тетраэдрическим марганцем после радиационного разрушения, то такая связь хотя и возможна, но далеко не обязательна. Второе важное обстоятельство заключается в низкой устойчивости тетраэдрического окружения марганца в разрушенной радиацией решетке тетрабората лития. Напомним, в правой части верхней панели рис. 2 показана деградация свечения $\mathrm{Li}_{2} \mathrm{~B}_{4} \mathrm{O}_{7}: \mathrm{Be}+\mathrm{Mn}$ при возбуждении его лазером на длине волны $350 \mathrm{~nm}$. Как зеленое, так и оранжевое свечение пропадают вместе, и только на последних стадиях деградации оранжевое становится чуть более заметным. Скорее всего, в случае зеленой люминесценции мы имеем дело с парными ионами $\mathrm{Mn}^{2+}$ в различном кислородном окружении, которые, будучи 
возбуждены лазерным импульсом, имеют помимо излучательной релаксации и другой канал - фотохимическую реакцию с образованием $\mathrm{Mn}^{3+}$. Окисление марганца может, например, быть результатом двухфотонного процесса фотоионизации. При этом люминесценция $\mathrm{Mn}^{2+}$ исчезает.

В пользу нашей модели говорит упомянутый в работе [21] факт, что зеленая люминесценция никогда не возбуждается по рекомбинационному механизму. Действительно, дырка будет не только отталкиваться от положительно заряженного марганцевого кластера, но и не сможет приблизиться к такому парному центру, возникшему в зоне поврежденной радиацией структуры с разрушенными химическими связями. Чтобы напрямую проверить, имеем ли мы дело с парными центрами марганца или все-таки с одиночными, следовало бы в дальнейшем измерить время затухания зеленой люминесценции, которое в случае парных центров должно оказаться более коротким.

Таким образом, в нашем случае лазер лишь „добива-

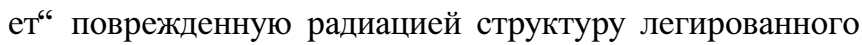
марганцем тетрабората лития. Роль же таких примесей, как бериллий или цинк, объясняется тем, что они усиливают кластеризацию марганца, а неоднородное распределение марганца провоцирует радиационную деградацию кристалла [45].

Для прямого лазерного разрушения кристалла требуются, на первый взгляд, гораздо большие удельные мощности. Тем не менее это не совсем так: легированный медью тетраборат лития эффективно разрушается в наших экспериментах и без предварительного радиационного воздействия, однако это тема отдельной работы.

\section{Заключение}

Исследование деградации термолюминесцентных материалов $\mathrm{Li}_{2} \mathrm{~B}_{4} \mathrm{O}_{7}: \mathrm{Be}+\mathrm{Mn}$ и $\mathrm{Li}_{2} \mathrm{~B}_{4} \mathrm{O}_{7}: \mathrm{Zn}+\mathrm{Mn}$ при комбинированном воздействии импульсного электронного пучка и лазерного излучения $350 \mathrm{~nm}$ показало: 1) под действием высоких доз радиации происходит аморфизация структуры тетрабората лития, и при этом формируются центры марганца с зеленой люминесценцией; 2) дальнейший распад центров люминесценции предположительно происходит путем окисления марганца $\mathrm{Mn}^{2+} \rightarrow \mathrm{Mn}^{3+}$ под действием лазерного возбуждения при $350 \mathrm{~nm}$. Самая низкая радиационная устойчивость оказалась у материала $\mathrm{Li}_{2} \mathrm{~B}_{4} \mathrm{O}_{7}: \mathrm{Be}+\mathrm{Mn}$.

Основной практический вклад данной работы связан с высоким интересом к считыванию радиационных детекторов путем оптической стимуляции вместо термической. При таком способе считывания как раз и возникают условия, подобные нашему случаю, хотя и не столь экстремальные как по дозе радиации, так и по мощности последующего облучения. Тем не менее важно знать, какие примеси могут снижать устойчивость материала и привести к дозиметрическим ошибкам.

\section{Благодарности}

Александр Селюков благодарит за поддержку Российский фонд фундаментальных исследований (в рамках проекта № 18-02-00811 А).

\section{Финансирование}

Финансирование работы осуществлялось частично в рамках Госзадания Института спектроскопии РАН и частично в рамках гранта РФФИ (проект № 18-0200811 A).

\section{Конфликт интересов}

Авторы заявляют, что у них нет конфликта интересов.

\section{Список литературы}

[1] Kwon T.Y., Ju J.J., Cha J.W., Kim J.N., Yun S.I. // Mater. Lett. 1994. V. 20 N 3-4 P. 211-215. doi 10.1016/0167577X(94)90089-2

[2] Kaminskii A.A., Bohatý L., Becker P., Liebertz J., Eichler H.J., Rhee H. // Laser Phys. Lett. 2006. V. 3. N 11. P. 519-530. doi 10.1002/lapl.200610053

[3] Komatsu R., Sugawara T., Sassa K., Sarukura N., Liu Z., Izumida S., Segawa Y., Uda S., Fukuda T., Yamanouchi K. // Appl. Phys. Lett. 1997. V. 70. N 26. P. 3492-3494. doi $10.1063 / 1.119210$

[4] Petrov V., Rotermund F., Noack F., Komatsu R., Sugawara T., Uda S. // J. Appl. Phys. 1998. V. 84. N 11. P. 5887-5892. doi 10.1063/1.368904

[5] Kitis G., Furetta C., Prokić M., Prokić V. // J. Phys. D: Appl. Phys. 2000. V. 33. N 11. P. 1252-1262. doi 10.1088/0022$3727 / 33 / 11 / 302$

[6] Podgórska D., Kaczmarek S.M., Drozdowski W., Wabia M., Kwaśny M., Warchot S., Rizak V.M. // Molecul. Phys. Rep. 2004. V. 39. P. 199-222.

[7] Holovey V.M., Sidey V.I., Lyamayev V.I., Birov M.M. // J. Phys. Chem. Solids 2007. V. 68. N 7. P. 1305-1310. doi 10.1016/j.jpcs.2007.02.005

[8] Kelemen A., Ignatovych M., Holovey V., Vidóczy T., Baranyai P. // Radiat. Phys. Chem. 2007. V. 76. N 8-9. P. 1531-1534. doi 10.1016/j.radphyschem.2007.02.067

[9] Holovey V.M., Sidey V.I., Lyamayev V.I., Birov M.M. // J. Phys. Chem. Solids 2007. V. 68 N 7. P. 1305-1310. doi 10.1016/j.jpcs.2007.02.005

[10] Danilkin M., Jaek I., Kerikmäe M., Lust A., Mändar H., Pung L., Ratas A., Seeman V., Klimonsky S., Kuznetsov V. // Radiat. Meas. 2010. V. 45. N 3-6. P. 562-565. doi 10.1016/j.radmeas.2010.01.045

[11] Kar S., Verma S., Bartwal K.S. // Phys. B. 2010. V. 405. N 20. P. 4299-4302. doi 10.1016/j.physb.2010.07.030

[12] Holovey V.M., Popovich K.P., Goyer D.B., Krasylynets V.M., Gomonnai A.V. // Radiat. Eff. Defects Solids. 2011. V. 166. N 7. P. 522-528. doi 10.1080/10420150.2011.559235

[13] Annalakshmi O., Jose M.T., Amarendra G. // Radiat. Meas. 2011. V. 46. N 8. P. 669-675. doi $0.1016 /$ j.radmeas.2011.06.016

[14] Kayhan M., Yilmaz A. // J. Alloys Compd. 2011. V. 509. N 30. P. 7819-7825. doi 10.1016/j.jallcom.2011.04.137 
[15] Ignatovych M., Fasoli M., Kelemen A. // Radiat. Phys. Chem. 2012. V. 81. N 9. P. $1528-1532$. doi 10.1016/j.radphyschem.2012.01.042

[16] Ozdemir A., Yegingil Z., Nur N., Kurt K., Tuken T., Depci T., Tansug G., Altunal V., Guckan V., Sigircik G., Yu Y., Karatasli M., Dolek Y. // J. Lumin. 2016. V. 173. P. 149-158. doi 10.1016/j.jlumin.2016.01.013

[17] Ratas A., Danilkin M., Kerikmäe M., Lust A., Mändar H., Seeman V., Slavin G. // P. Est. Acad. Sci. 2012. V. 61. N 4. P. 279-295. doi 10.3176/proc.2012.4.03

[18] Nagirnyi V., Aleksanyan E., Corradi G., Danilkin M., Feldbach E., Kerikmäe M., Kotlov A., Lust A., Polgśr K., Ratas A., Romet I., Seeman V. // Radiat. Meas. 2013. V. 56. P. 192-195. doi 10.1016/j.radmeas.2013.02.005

[19] Kelly T.D., Kong L., Buchanan D.A., Brant A.T., Petrosky J.C., McClory J.W., Adamiv V.T., Burak Y.V., Dowben P.A. // Phys. Status Solidi B 2013. V. 250 N 7. P. 1376-1383. doi $10.1002 / p s s b .201349013$

[20] Dugan C., Hengehold R.L., McHale S.R., Colón Santana J.A., McClory J.W., Adamiv V.T., Burak Ya.V., Losovyj Ya.B., Dowben P.A. // Appl. Phys. Lett. 2013. V. 102. N 16. P. 161602. doi 10.1063/1.4802760

[21] Romet I., Buryi M., Corradi G., Feldbach E., Laguta V., TichyRács É., Nagirnyi V. // Opt. Mater. 2017. V. 70. P. 184-193. doi 10.1016/j.optmat.2017.05.032

[22] Brant A.T., Kananan B.E., Murari M.K., McClory J.W., Petrosky J.C., Adamiv V.T., Burak Ya.V., Dowben P.A., Halliburton L.E. // J. Appl. Phys. 2011. V. 110. N 9. P. 093719. doi $10.1063 / 1.3658264$

[23] Brant A.T., Buchanan D.A., McClory J.W., Adamiv V.T., Burak Ya.V., Halliburton L.E., Giles N.C. // J. Lumin. 2014. V. 153. P. 79-84. doi 10.1016/j.jlumin.2014.03.008

[24] Buchanan D.A., Holston M.S., Brant A.T., McClory J.W., Adamiv V.T., Burak Ya.V., Halliburton L.E. // J. Phys. Chem. Solids 2014. V. 75. N 12. P. 1347-1353. doi 10.1016/j.jpcs.2014.07.014

[25] Patra G.D., Singh S.G., Singh A.K., Tyagi M., Desai D.G., Tiwari B., Sen S., Gadkari S.C. // J. Lumin. 2015. V. 157. P. 333-337. doi 10.1016/j.jlumin.2014.09.017

[26] Patra G.D., Singh S.G., Tiwari B., Singh A.K., Desai D.G., Tyagi M., Sen S., Gadkari S.C. // Radiat. Meas. 2016. V. 88 P. 14-19. doi 10.1016/j.radmeas.2016.03.002

[27] Romet I., Aleksanyan E., Brik M.G., Corradi G., Kotlov A., Nagirnyi V., Polgár K. // J. Lumin. 2016. V. 177. P. 9-16. doi 10.1016/j.jlumin.2016.04.014

[28] Celik M.G., Yilmaz A., Yazici A.N. // Radiat. Meas. 2017. V. 102. P. 16-26. doi 10.1016/j.radmeas.2017.06.002

[29] Prokić M. // Radiat. Meas. 2001. V. 33. N 4. P. 393-396. doi 10.1016/S1350-4487(01)00039-7

[30] Can N., Karali T., Townsend P.D., Yıldız F. // J. Phys. D: Appl. Phys. 2006. V. 39. N 10. P. 2038-2043. doi 10.1088/0022$3727 / 39 / 10 / 009$

[31] Corradi G., Watterich A., Polgár K., Nagirnyi V., Hofstaetter A., Rakitina L.G., Meyer M. // Phys. Status Solidi C. 2007. V. 4 N 3. P. 1276-1279. doi 10.1002/pssc.200673756

[32] Corradi G., Nagirnyi V., Kotlov A., Watterich A., Kirm M., Polgár K., Hofstaetter A., Meyer M. // J. Phys.: Condens. Matter. 2008. V. 20. N 2. P. 025216. doi 10.1088/0953$8984 / 20 / 02 / 025216$

[33] Corradi G., Nagirnyi V., Watterich A., Kotlov A., Polgár K. // J. Phys.: Conf. Ser. 2010. V. 249. N 1. P. 012008. doi 10.1088/1742-6596/249/1/012008

[34] Huy B.T., Quang V.X., Ishii M. // J. Lumin. 2010. V. 130. N 11. P. 2142-2145. doi 10.1016/j.jlumin.2010.06.008
[35] Kelemen A., Mesterházy D., Ignatovych M., Holovey V. // Radiat. Phys. Chem. 2012. V. 81. N 9. P. 1533-1535. doi 10.1016/j.radphyschem.2012.01.041

[36] Brant A.T., Buchanan D.A., McClory J.W., Dowben P.A., Adamiv V.T., Burak Ya.V., Halliburton L.E. // J. Lumin. 2013. V. 139 P. 125-131. doi 10.1016/j.jlumin.2013.02.023

[37] Aydin T., Demirtas H., Aydin S. // Radiat. Meas. 2013. V. 58 P. 24-32. doi 10.1016/j.radmeas.2013.07.010

[38] Маловичко Г.И., Витрук Л.Е., Юрченко Н.Ю., Бурак Я.В., Грачев В.Г., Матковский А.О., Сугак Д.Ю. // ФТТ. 1992. T. 34. № 2. C. 509-512.

[39] Matkovskii A.O., Sugak D.Yu., Burak Ya.V., Malovichko G.I., Grachov V.G. // Radiat. Eff. Defects Solids. 1994. V. 132. N 4. P. 371-376. doi 10.1080/10420159408219989

[40] Огородников И.Н., Яковлев В.Ю., Кружалов А.В., Исаенко Л.И. // ФТТ. 2002. Т. 44. № 6. С. 1039-1047; Ogorodnikov I.N., Yakovlev V.Y., Kruzhalov A.V., Isaenko L.I. // Phys. Solid State. 2002. V. 44. N 6. P. 1085-1092. doi 10.1134/1.1485012

[41] Burak Ya.V., Padlyak B.V., Shevel V.M. // Radiat. Eff. Defects Solids. 2002. V. 157. N 6-12. P. 1101-1109. doi 10.1080/10420150215791

[42] Burak Ya.V., Padlyak B.V., Shevel V.M. // Nucl. Instrum. Methods Phys. Res., Sect. B. 2002. V. 191. N 1-4. P. 633-637. doi 10.1016/S0168-583X(02)00624-9

[43] Swinney M.W., McClory J.W., Petrosky J.C., Yang Sh., Brant A.T., Adamiv V.T., Burak Ya.V., Dowben P.A., Halliburton L.E. // J. Appl. Phys. 2010. V. 107. N 11. P. 113715. doi 10.1063/1.3392802

[44] Ogorodnikov I.N., Poryvay N.E., Pustovarov V.A. // IOP Conf. Ser: Mater. Sci. Eng. 2010. V. 15. N 1. P. 012016. doi 10.1088/1757-899X/15/1/012016

[45] Danilkin M.I., Koksharov Yu.A., Romet I., Seeman V.O., Vereschagina N.Yu., Zubov A.I., Selyukov A.S. // Radiat. Meas. 2019. doi 10.1016/j.radmeas.2019.106134.

[46] Vereschagina N.Yu., Danilkin M.I., Kazaryan M.A., Ozol D.I., Sheshin E.P., Spassky D.A. // Proc. SPIE 2018. V. 10614. P. 106141F. doi 10.1117/12.2303579

[47] Верещагина Н.Ю., Данилкин М.И. Патент РФ № 2660866 C1, 2018.

[48] Афанасьев В.Н., Бычков В.В., Лариев В.Д., Пудов В.П., Соломонов В.И., Шунайлов С.А., Генералова В.В., Громов А.A. // ПТЭ. 2005. № 5. С. 88-92; Afanas'ev V.N., Bychkov V.B., Lartsev V.D., Pudov V.P., Solomonov V.I., Shunailov S.A., Generalova V.V., Gromov A.A. // Instrum. Exp. Tech. 2005. V. 48 N 5. P. 641-645. doi 10.1007/s10786-0050114-y

[49] Kerikmäe M., Danilkin M., Lust A., Nagirnyi V., Pung L., Ratas A., Romet I., Seeman V. // Radiat. Meas. 2013. V. 56. P. 147-149. doi 10.1016/j.radmeas.2013.02.002

[50] Lin H., Zhang R., Chen D., Yu Y., Yang A., Wang Y. // J. Mater. Chem. C. 2013. V. 1. N 9. P. 1804-1811. doi $10.1039 / \mathrm{C} 2 \mathrm{TC} 00658 \mathrm{H}$

[51] Shi L., Huang Y., Seo H.J. // J. Phys. Chem. A. 2010. V. 114. N 26. P. 6927-6934. doi 10.1021/jp101772z

[52] Szōllösy L., Szōrényi T., Szanka K. // Acta Phys. et Chem. Szeged. 1975. V. 21. P. 119-122.

[53] Szōllösy L., Szōrönyi T., Szanka K. // Acta Phys. et Chem. Szeged. 1974. V. 20. P. 299-304.

[54] Щербаков В.Д. // Учен. зап. Казан.ун-та. Сер. Физ.-матем. науки. 2015. Т. 157 № 4. С. 172-181. 